\title{
Increased Tolerance to Furfural by Introduction of Polyhydroxybutyrate Synthetic Genes to Escherichia coli
}

\author{
Hye-Rim Jung ${ }^{1}$, Ju-Hee Lee ${ }^{1}$, Yu-Mi Moon ${ }^{1}$, Tae-Rim Choi ${ }^{1}$, Soo-Yeon Yang ${ }^{1}$, Hun-Suk Song ${ }^{1}$, Jun Young Park ${ }^{1}$, \\ Ye Lim Park ${ }^{1}$, Shashi Kant Bhatia ${ }^{1,2}$, Ranjit Gurav ${ }^{1}$, Byoung Joon $\mathrm{Ko}^{3}$, and Yung-Hun Yang ${ }^{1,2 *}$ \\ ${ }^{1}$ Department of Biological Engineering, College of Engineering, Konkuk University, Seoul 05029, Republic of Korea \\ ${ }^{2}$ Institute for Ubiquitous Information Technology and Applications (CBRU), Konkuk University, Seoul 05029, Republic of Korea \\ ${ }^{3}$ New Drug Development Center, Osong Medical Innovative Foundation, Cheongju 28160, Republic of Korea
}

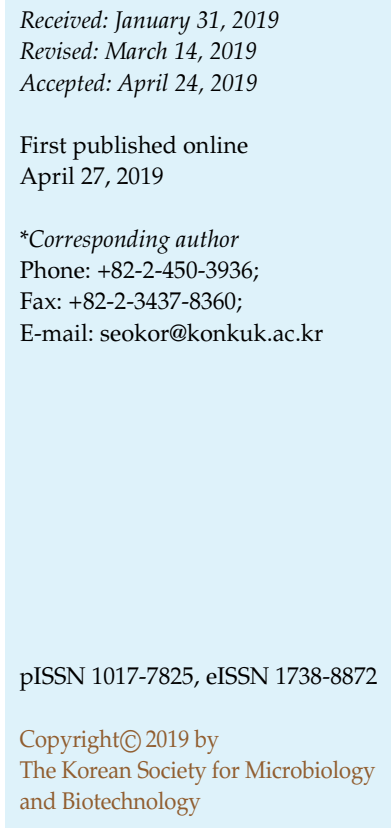

Polyhydroxybutyrate (PHB), the most well-known polyhydroxyalkanoate, is a bio-based, biodegradable polymer that has the potential to replace petroleum-based plastics. Lignocellulose hydrolysate, a non-edible resource, is a promising substrate for the sustainable, fermentative production of PHB. However, its application is limited by the generation of inhibitors during the pretreatment processes. In this study, we investigated the feasibility of PHB production in E. coli in the presence of inhibitors found in lignocellulose hydrolysates. Our results show that the introduction of PHB synthetic genes $(b k t B$, phaB, and phaC from Ralstonia eutropha H16) improved cell growth in the presence of the inhibitors such as furfural, 4-hydroxybenzaldehyde, and vanillin, suggesting that PHB synthetic genes confer resistance to these inhibitors. In addition, increased PHB production was observed in the presence of furfural as opposed to the absence of furfural, suggesting that this compound could be used to stimulate PHB production. Our findings indicate that PHB production using lignocellulose hydrolysates in recombinant $E$. coli could be an innovative strategy for cost-effective PHB production, and PHB could be a good target product from lignocellulose hydrolysates, especially glucose.

Keywords: Polyhydroxybutyrate, furfural, resistance, Escherichia coli, lignocellulose hydrolysate

\section{Introduction}

Lignocellulosic biomass is an abundant renewable resource for the production of biofuels, chemicals, and polymers [1-3]. Lignocellulose is mainly composed of three polymers, cellulose, hemicellulose, and lignin, together with other components, such as acetate, minerals, and phenolic substituents [4]. However, the main impediments in utilizing lignocellulose materials lie in the crystalline structure of cellulose sheathed by hemicellulose, degree of polymerization, biomass particle size, and recalcitrance of their bonding due to the protective covering of lignin [5]. To better utilize this biomass and efficiently extract carbohydrates, pretreatment processes are necessary [6-8]. Various pretreatment processes have been developed to purify sugar compounds, one of which is acid hydrolysis
$[9,10]$. However, in pretreatment processes, several unwanted inhibitors (e.g., furfural, 4-hydroxybenzaldehyde, vanillin, and acetate) are also produced [11, 12]. The quantity of these inhibitors depends on the type of biomass and the hydrolysis condition [13]. Among them, furfural is a major toxic byproduct from pretreated lignocellulose. Furfural is derived from pentose, and it damages DNA and inhibits glycolysis and sugar metabolism [13-15]. Furfural is converted to the less toxic furfuryl alcohol through reduction by aldehyde reductases [16]. To overcome the inhibitory effects of furfural, genes encoding NADHdependent furfural reductase (FucO), NADPH-dependent oxidoreductase (YqhD), membrane-bound transhydrogenase interconverting NADH and NADPH (PntAB), and NAD salvage pathway (PncB, NadE) have been used to provide furfural resistance [17-20]. 
The polyhydroxyalkanoate (PHA) family of bio-based, biodegradable polymers is a promising next-generation product that can potentially substitute for petroleum-based plastics and is synthesized by many microorganisms as part of their natural metabolism [21,22]. Previous studies on bacterial PHA accumulation have shown that it is largely affected by nutrient conditions, such as nitrogen and phosphate concentrations, and oxygen limitation [2325]. Compared to petroleum-based plastics, PHA has many advantages including biodegradability and biocompatibility, while its thermal and mechanical properties are similar to those of petroleum-based plastics [26]. The most extensively studied member of the PHA family is poly(3hydroxybutyrate)(PHB) [27]. The biosynthesis of $\mathrm{PHB}$ requires three reactions mediated by $\beta$-ketothiolase (BktB), acetoacetyl-CoA reductase (PhaB), and $\mathrm{PHB}$ polymerase (PhaC).

Bio-based resources are renewable and are expected to play a key role in the production of novel bio-based materials, contributing to a reduction in the negative environmental impact of petroleum-based products and thus addressing the bio-economy of the future [4]. The increasing worldwide need for bio-based plastic production will, therefore, be an important driver towards the use of renewable non-edible sources, such as lignocellulosic biomass [28]. To date, research has focused on the development of new bacterial strains and the discovery of cost-effective starting materials for PHB production [27, 29]. A number of bacteria that produce PHB from lignocellulosederived monosaccharides have been identified [30-33].
However, their application is limited to using hydrolysates containing only small amounts of inhibitors or after eliminating toxic compounds $[29,31,34]$. Therefore, discovering an effective detoxification strategy remains important for efficient utilization of biomass hydrolysate for microbial growth and fermentation.

In this study, we investigated the feasibility of PHB production in Escherichia coli in the presence of inhibitors such as furfural. Interestingly, we found an association between furfural and PHB production in E. coli, in which PHB synthetic genes provided high resistance to furfural and the compound itself stimulated PHB production.

\section{Materials and Methods}

\section{Bacterial Strains, Media, Reagents, and Culture Conditions}

Strains and plasmids used in this study are listed in Table 1. E. coli $\mathrm{DH} 5 \alpha$ and $\mathrm{KSYH}(\mathrm{DE} 3)$ were used as host strains for gene cloning and PHB production, respectively [35-37]. For cell preparation and selection of transformants, the strains were cultured in lysogeny broth (LB) agar and/or liquid broth. LB agar was prepared by dissolving $10 \mathrm{~g}$ of tryptone, $5 \mathrm{~g}$ of yeast extract, $10 \mathrm{~g}$ of $\mathrm{NaCl}$, and $15 \mathrm{~g}$ of agar in $1 \mathrm{~L}$ of distilled water. For evaluation of furfural resistance and PHB production, transformants were cultured in M9 minimal medium containing $2 \%$ glucose and $0.1 \%$ yeast extract, which had an initial $\mathrm{pH}$ of 6.8 . Appropriate antibiotics $(100 \mu \mathrm{g} / \mathrm{ml}$ spectinomycin and $25 \mu \mathrm{g} / \mathrm{ml}$ chloramphenicol for E. coli transformants) were added when required, and $0.1 \mathrm{mM}$ isopropyl- $\beta$-D-thiogalactoside (IPTG) was added at the beginning of culture. For preculture, a single colony from an LB agar plate was inoculated into $3 \mathrm{ml}$ of LB broth. The

Table 1. Bacterial strains, plasmids, and primers used in this study.

\begin{tabular}{|c|c|c|}
\hline Strain or plasmid & Description & Reference \\
\hline \multicolumn{3}{|l|}{ E. coli strains } \\
\hline $\mathrm{DH} 5 \alpha$ & General cloning strain & Invitrogen \\
\hline KSYH(DE3) & BW25113 derivative containing DE3, $\triangle a r a B A D, \triangle r h a B A D$ & [35] \\
\hline $\mathrm{KSYH}(\mathrm{DE} 3) / \mathrm{pCDF}$ & KSYH(DE3) containing pCDFDuet-1 & This study \\
\hline $\mathrm{KSYH}(\mathrm{DE} 3):: b k t B$ & KSYH(DE3) containing pCDF:: bktB & This study \\
\hline KSYH(DE3)::phaB & KSYH(DE3) containing pCDF::phaB & This study \\
\hline KSYH(DE3)::phaC & KSYH(DE3) containing pCDF::phaC & This study \\
\hline YH090 & KSYH(DE3) containing pLW487 & [35] \\
\hline \multicolumn{3}{|l|}{ Plasmids } \\
\hline pCDFDuet-1 & A compatible spectinomycin-selectable plasmid carrying T7/lac promoter & Novagen \\
\hline $\mathrm{pCDF}:: b k t B$ & pCDFDuet-1 carrying $b k t B$ gene from Ralstonia eutropha $\mathrm{H} 16$ & This study \\
\hline pCDF::phaB & pCDFDuet-1 carrying phaB gene from Ralstonia eutropha H16 & This study \\
\hline pCDF::phaC & pCDFDuet-1 carrying phaC gene from Ralstonia eutropha H16 & This study \\
\hline pLW487 & $\begin{array}{l}\text { Spectinomycin-selectable pEP2-based plasmid carrying } b k t B \text {, phaB and } p h a C \text { genes from } \\
\text { Ralstonia eutropha } \mathrm{H} 16 \text { under the control of } \operatorname{trc} \text { promoter. }\end{array}$ & [48] \\
\hline
\end{tabular}


Table 2. Composition of lignocellulose hydrolysates from Miscanthus, barley straw, and pine tree used in this study.

\begin{tabular}{|c|c|c|c|}
\hline \multirow{2}{*}{$\begin{array}{r}\text { Biomass } \\
\text { Miscanthus }\end{array}$} & \multicolumn{2}{|c|}{ Components } & \multirow{2}{*}{$\begin{array}{c}\text { Concentration }(\mathrm{g} / \mathrm{l}) \\
102.19 \pm 0.54\end{array}$} \\
\hline & Monosugars & Glucose & \\
\hline & & Xylose & $20.16 \pm 0.25$ \\
\hline & & Galactose & $1.42 \pm 0.21$ \\
\hline & & Arabinose & $2.97 \pm 0.17$ \\
\hline & & Mannose & $1.55 \pm 0.21$ \\
\hline & Byproducts & Formic acid & - \\
\hline & & Acetic acid & $0.24 \pm 0.01$ \\
\hline & & Levulinic acid & - \\
\hline & & 5-Hydroxymethylfurfural & $0.19 \pm 0.01$ \\
\hline & & Furfural & $0.48 \pm 0.01$ \\
\hline \multirow[t]{10}{*}{ Barley straw } & Monosugars & Glucose & $135.80 \pm 0.04$ \\
\hline & & Xylose & $13.164 \pm 0.67$ \\
\hline & & Galactose & - \\
\hline & & Arabinose & $0.34 \pm 0.01$ \\
\hline & & Mannose & $0.70 \pm 0.04$ \\
\hline & Byproducts & Formic acid & $0.17 \pm 0.03$ \\
\hline & & Acetic acid & $0.14 \pm 0.02$ \\
\hline & & Levulinic acid & - \\
\hline & & 5-Hydroxymethylfurfural & $0.18 \pm 0.01$ \\
\hline & & Furfural & $0.09 \pm 0.01$ \\
\hline \multirow[t]{10}{*}{ Pine tree } & Monosugars & Glucose & $127.44 \pm 0.22$ \\
\hline & & Xylose & $14.02 \pm 0.33$ \\
\hline & & Galactose & - \\
\hline & & Arabinose & - \\
\hline & & Mannose & $2.95 \pm 0.23$ \\
\hline & Byproducts & Formic acid & - \\
\hline & & Acetic acid & $0.88 \pm 0.02$ \\
\hline & & Levulinic acid & - \\
\hline & & 5-Hydroxymethylfurfural & $0.15 \pm 0.01$ \\
\hline & & Furfural & $0.17 \pm 0.01$ \\
\hline
\end{tabular}

culture was incubated overnight in a shaking incubator at $37^{\circ} \mathrm{C}$ and $200 \mathrm{rpm}$. For flask culture, grown cells were inoculated into $100 \mathrm{ml}$ of production medium in 250-ml screw-cap flasks at a dilution of 1:100 (v/v). The culture was continuously shaken in an incubator at $200 \mathrm{rpm}$ and $30^{\circ} \mathrm{C}$. Restriction enzymes and DNA polymerase were purchased from Enzynomics (Korea), plasmid extraction and gel purification kits from GeneAll (Korea), medium components from Bacto or Difco (USA), and furfural, vanillin, and 4-hydroxybenzaldehyde from Sigma-Aldrich (USA). Lignocellulose hydrolysates (Miscanthus, barley straw, and pine tree) were purchased from Sugaren (Korea) and their composition is described in Table 2 [8].

\section{DNA Manipulation}

Gene cloning was conducted according to standard protocols [38]. PHB synthetic genes (bktB, phaB, and phaC) were from
Ralstonia eutropha H16. In brief, each target gene was amplified by PCR, and the amplification product was purified and digested with restriction enzymes. The digested fragment was ligated into a plasmid, which was digested with the same restriction enzymes. Ligated plasmids were transformed into E. coli DH5 $\alpha$ using the heat-shock method. Constructed plasmids were used for further study only after they were confirmed by sequencing. Detailed information is shown in Table 1.

\section{Analytical Methods}

PHB production was determined by gas chromatography and a slightly modified version of a previously described method [39, 40]. For analysis, culture samples were centrifuged at 10,000 $\times g$ for $10 \mathrm{~min}$, washed with deionized water twice, and suspended in $1 \mathrm{ml}$ of water. The suspended samples were lyophilized, weighed, and placed in Teflon-stoppered glass vials. For methanolysis of 
PHB samples, $1 \mathrm{ml}$ of chloroform and $1 \mathrm{ml}$ of a methanol/sulfuric acid $(85: 15, \mathrm{v} / \mathrm{v})$ mixture were added to the vials, which were then incubated at $100^{\circ} \mathrm{C}$ for $2 \mathrm{~h}$. Samples were cooled to room temperature and incubated on ice for approximately $10 \mathrm{~min}$. After adding $1 \mathrm{ml}$ of ice-cold water, samples were thoroughly vortexmixed for $1 \mathrm{~min}$ and centrifuged at 2,000 $\times g$. The (lower) organic phase was collected using a pipette and transferred to a clean borosilicate glass tube containing anhydrous sodium sulfate $\left(\mathrm{Na}_{2} \mathrm{SO}_{4}\right)$. Then, the samples were injected into a gas chromatograph (Young Lin Tech, Korea) equipped with a DB-Wax column (30 m $\times 0.32 \mathrm{~mm} \times 0.5 \mu \mathrm{m})$ (Agilent Technologies, USA). The split ratio was $1: 10$. Helium was used as a carrier gas at a flow rate of $3.0 \mathrm{ml} / \mathrm{min}$. Two microliters of the organic phase was injected using an autosampler. The inlet was maintained at $210^{\circ} \mathrm{C}$. The column oven was held at $80^{\circ} \mathrm{C}$ for $5 \mathrm{~min}$, heated to $220^{\circ} \mathrm{C}$ at $20^{\circ} \mathrm{C} / \mathrm{min}$, and then held at $220^{\circ} \mathrm{C}$ for $5 \mathrm{~min}$. Peak detection was conducted using a flame ionization detector, which was maintained at $230^{\circ} \mathrm{C}$. Furfural concentrations were determined by gas chromatography as mentioned above, except that the column oven was held at $50^{\circ} \mathrm{C}$ for $5 \mathrm{~min}$, heated to $230^{\circ} \mathrm{C}$ at $20^{\circ} \mathrm{C} / \mathrm{min}$, and then held at $230^{\circ} \mathrm{C}$ for $5 \mathrm{~min}$.

\section{Results}

\section{Effects of PHB on Furfural Resistance}

It is well known that pretreatment of lignocellulose generates several potentially toxic compounds, such as organic acids and aldehydes (e.g., acetic acid, levulinic acid, 4-hydroxybenzaldehyde, vanillin, and furfural) [33]. Furfural is considered the most potent inhibitor of E. coli growth [41] and has various cell-inhibitory effects [17, 18, 42]. It damages DNA, affects the hydrophobicity of intracellular membranes and depletes $\mathrm{NAD}(\mathrm{P}) \mathrm{H}$ in the cell [18]. In addition to general toxicity, because both PHB synthesis and furfural detoxification require $\mathrm{NADH}$ and
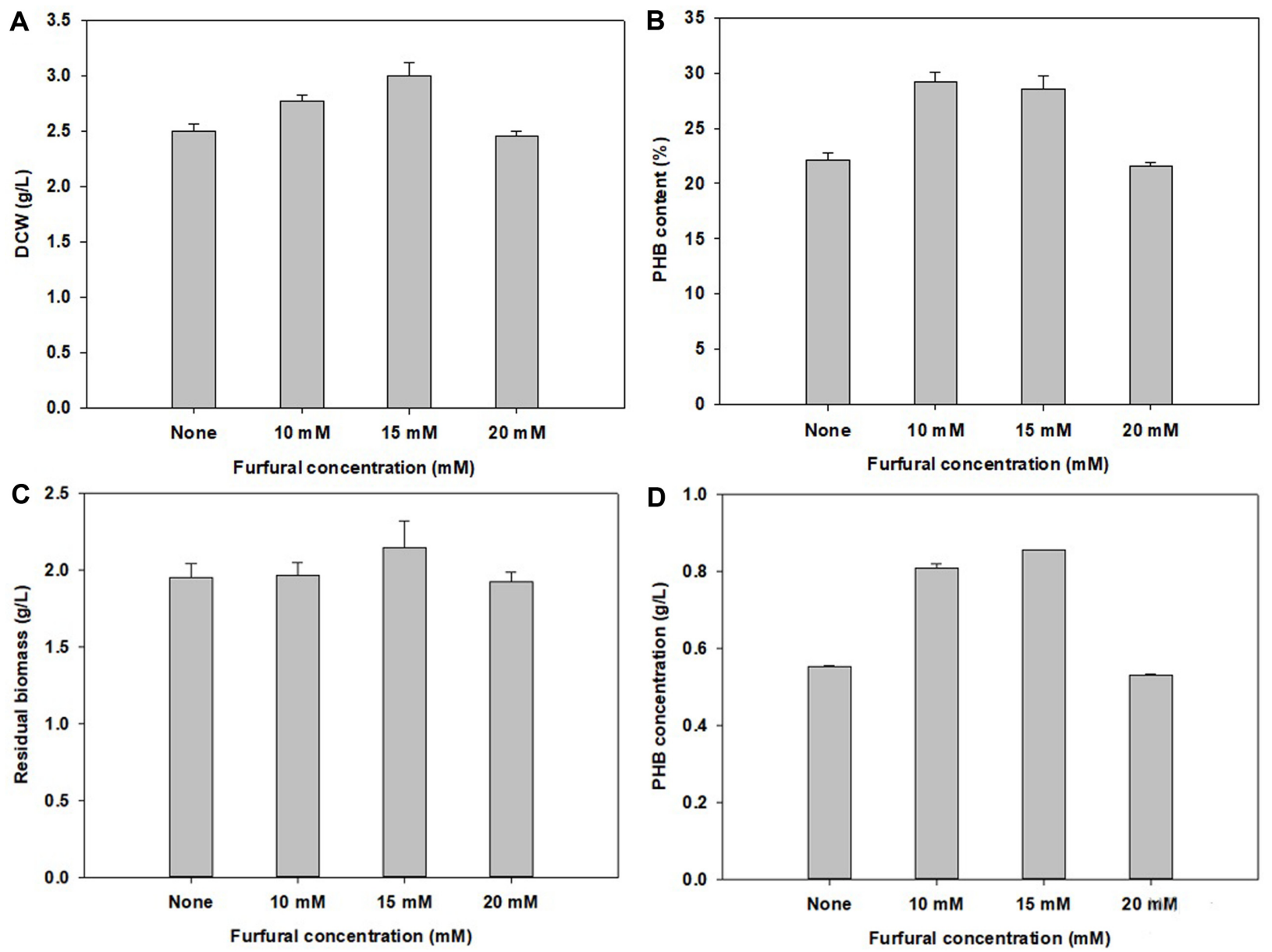

Fig. 1. Enhancement of polyhydroxybutyrate (PHB) production by furfural.

Cell growth and PHB production in E. coli YH090 (pLW487) were investigated in the presence of furfural. Furfural concentration ranged from 0 to 20 mM. (A) DCW (dry cell weight, g/l), (B) PHB content (w/w \%), (C) Residual biomass (g/l), and (D) PHB concentration (g/l). Cells were grown for $72 \mathrm{~h}$. Error bars represent the standard deviation of two replicates. 
NADPH as cofactors, cofactor depletion affects cell growth and productivity in E. coli and R. eutropha H16 [17, 18, 30, $33,42]$. Therefore, when cell growth and PHB content were monitored in E. coli YH090 containing PHB synthetic genes in the presence of different concentrations of furfural, we expected to observe a decrease in cell growth. However, interestingly, in the presence of $15 \mathrm{mM}$ furfural, E.coli YH090 cell growth and PHB content were respectively 1.2fold and 1.3-fold higher than in the absence of furfural, and the highest PHB concentration of $0.85 \mathrm{~g} / 1$ was noted in this condition (Figs. 1A, 1B, and 1D). When more than $20 \mathrm{mM}$ furfural was used, introducing PHB synthetic genes had no effect on furfural resistance. The residual biomass, defined as dry cell weight excluding that of $\mathrm{PHB}$, was constant at different concentrations of furfural (Fig. 1C). These results are consistent with previous reports that E. coli does not contain furfural oxidative degradation pathways and is unable to catabolize furfural as a carbon source [43]. Although it is well known that furfural inhibits sugar metabolism, such as glycolysis, carbon assimilation is accelerated along with PHB accumulation in the presence of furfural (Figs. 1B and 1D) [13].

To confirm that $\mathrm{PHB}$ production is increased in the presence of furfural, we monitored PHB production with or without $15 \mathrm{mM}$ furfural in E. coli YH090 for $72 \mathrm{~h}$ (Fig. 2). During the initial $24 \mathrm{~h}$ of cultivation, cell growth and PHB production were lower in the presence of $15 \mathrm{mM}$ furfural than in the absence of furfural. However, after $24 \mathrm{~h}$ of cultivation in the presence of $15 \mathrm{mM}$ furfural, cell growth and PHB content sharply increased and, at $72 \mathrm{~h}$, cell growth was 1.55-fold higher and the PHB concentration was 4-fold higher than in the absence of furfural (Fig. 2). Therefore, addition of $15 \mathrm{mM}$ furfural strongly stimulated cell growth and PHB production. The mechanisms underlying these effects, however, remain to be elucidated.

\section{Investigation of Furfural Resistance Induced by Individual Genes and the Protective Effect against Lignocellulose- Derived Inhibitors}

It is widely known that many reductases are effective for inducing furfural resistance $[19,20,44]$. Similarly, we expected that PhaB, an NADPH-dependent acetoacetylCoA reductase, would be effective in restoring cell growth and improving PHB production in the presence of furfural. Thus, to determine which gene was responsible for increased cell growth and PHB production in the presence of furfural, individual gene ( $p h a B)$ of the PHB synthesis pathway was overexpressed separately in $E$. coli $\mathrm{KSYH}(\mathrm{DE} 3)$, and cell growth and the furfural conversion rate were evaluated for $24 \mathrm{~h}$ (Fig. 3). Contrary to our expectations, KSYH(DE3) strains containing individual gene $(p h a B)$ separately showed no clear difference in cell growth and furfural conversion rate (Fig. 3). In contrast, E. coli YH090 strain containing the three PHB synthetic genes showed notably improved cell growth and the highest furfural conversion rate during $24 \mathrm{~h}$ cultivation. During the initial $6 \mathrm{~h}$ of cultivation, this YH090 strain showed significantly lower cell growth and furfural conversion rate than the other strains; however, after $12 \mathrm{~h}$ cultivation, cell growth was completely restored, and the furfural conversion rate was the highest observed. These results were consistent with the findings that E. coli YH090
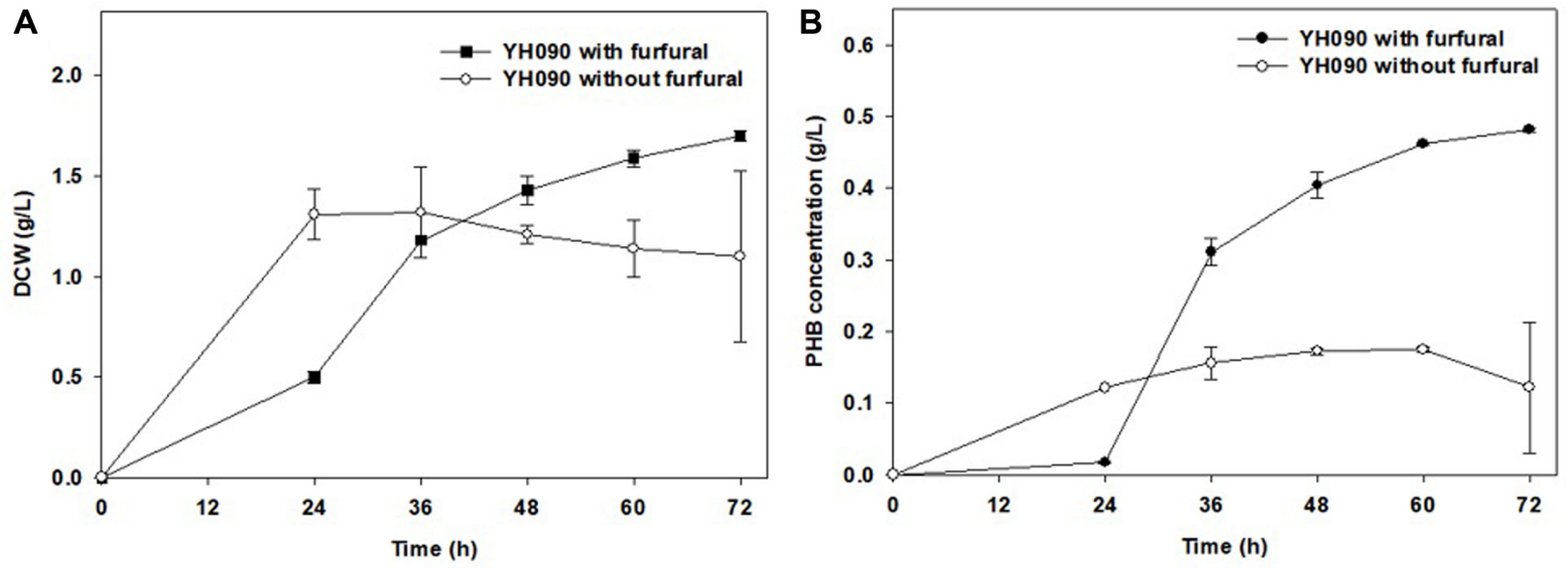

Fig. 2. Time-course profiles of polyhydroxybutyrate (PHB) production in E. coli $\mathrm{YH} 090$ in the presence or absence of furfural. (A) DCW (dry cell weight, g/l) and (B) PHB concentration (g/l). Error bars represent the standard deviation of two replicates. 

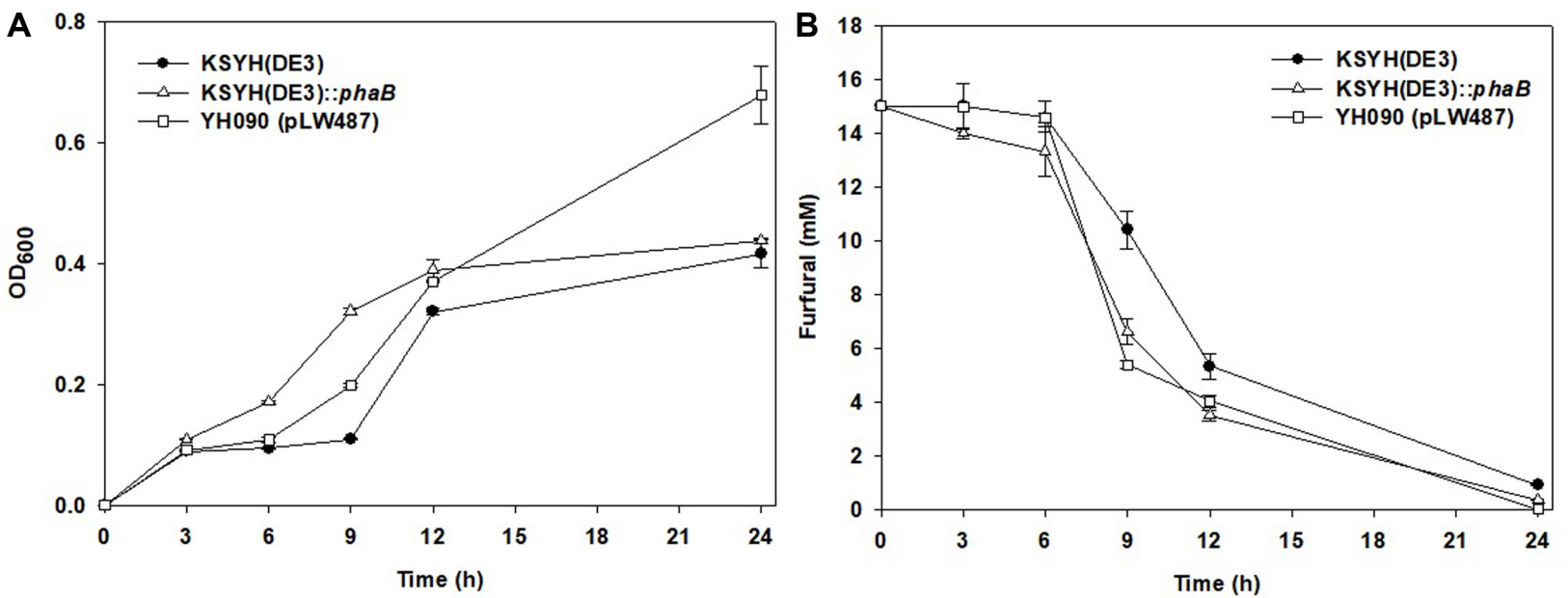

Fig. 3. Effects of overexpression of PHB synthetic genes on cell growth and furfural consumption.

(A) Optical density (OD) at $600 \mathrm{~nm}$ and (B) Furfural concentration (mM). Cells were grown for $24 \mathrm{~h}$. Error bars represent the standard deviation of two replicates.

showed a longer lag phase in cell growth and PHB production in the presence of furfural as discussed above (Fig. 2). Based on these findings, we conclude that furfural resistance depends on the overexpression of the three PHB synthetic genes, not any individual gene of the PHB synthesis pathway.

To test whether introducing PHB synthetic genes might affect resistance to other lignocellulose-derived inhibitors, such as vanillin and 4-hydroxybenzaldehyde, cell growth of E. coli KSYH(DE3) and YH090 was evaluated in medium

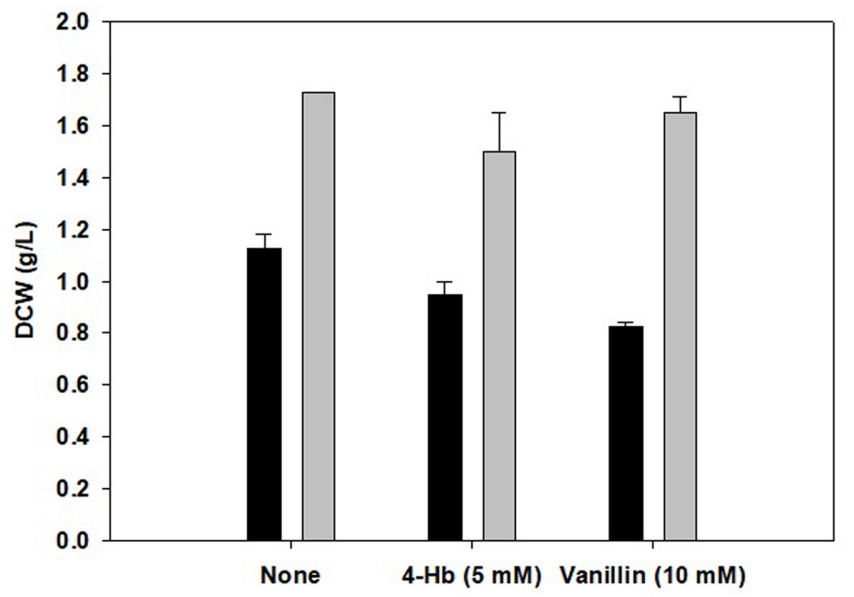

Fig. 4. Increased resistance to lignocellulose-derived inhibitors. Inhibitory effects of lignocellulose-derived inhibitors and protective effects of PHB synthesis were investigated. 4-Hydroxybenzaldehyde (4- $\mathrm{Hb}, 5 \mathrm{mM})$ and vanillin $(10 \mathrm{mM})$ were used. DCW, dry cell weight, $\mathrm{g} / \mathrm{l}$. Cells were grown for $48 \mathrm{~h}$. containing 4-hydroxybenzaldehyde $(5 \mathrm{mM})$ or vanillin $(10 \mathrm{mM})$ [42]. Similar to our findings for furfural, when the three PHB synthetic genes were introduced, cell growth was increased by 1.58-fold and 2-fold in the presence of 4hydroxybenzaldehyde and vanillin, respectively (Fig. 4). We conclude that the introduction of PHB synthetic genes confers resistance not only to furfural, but also to vanillin and 4-hydroxybenzaldehyde.

\section{Effects of Lignocellulose Hydrolysates on PHB Production}

To evaluate the effects of lignocellulose hydrolysates on PHB production, E. coli $\mathrm{YH} 090$ was grown in M9 minimal medium containing lignocellulose hydrolysates. The composition of hydrolysates from Miscanthus, barley straw, and pine tree, which contain several inhibitors, are shown in Table 2. As the initial glucose concentration was adjusted to $2 \%$, each lignocellulose hydrolysate was diluted appropriately. Because only small amounts of pentose sugars (xylose and arabinose) were not detected by HPLC, their concentrations were ignored. To evaluate the effects of lignocellulose hydrolysates, cell growth and PHB production in synthetic medium containing M9 minimal medium and $2 \%$ glucose as a sole carbon source, without inhibitors, were also investigated. PHB production was significantly increased with increasing fermentation time, especially in the presence of hydrolysates of Miscanthus, barley straw, or pine tree. Especially, in the presence of Miscanthus hydrolysate, the PHB concentration reached $0.67 \mathrm{~g} / 1$ at $24 \mathrm{~h}, 1.06 \mathrm{~g} / 1$ at $48 \mathrm{~h}$, and $1.29 \mathrm{~g} / 1$ at $72 \mathrm{~h}$, corresponding to an approximately 2 -fold increase compared 

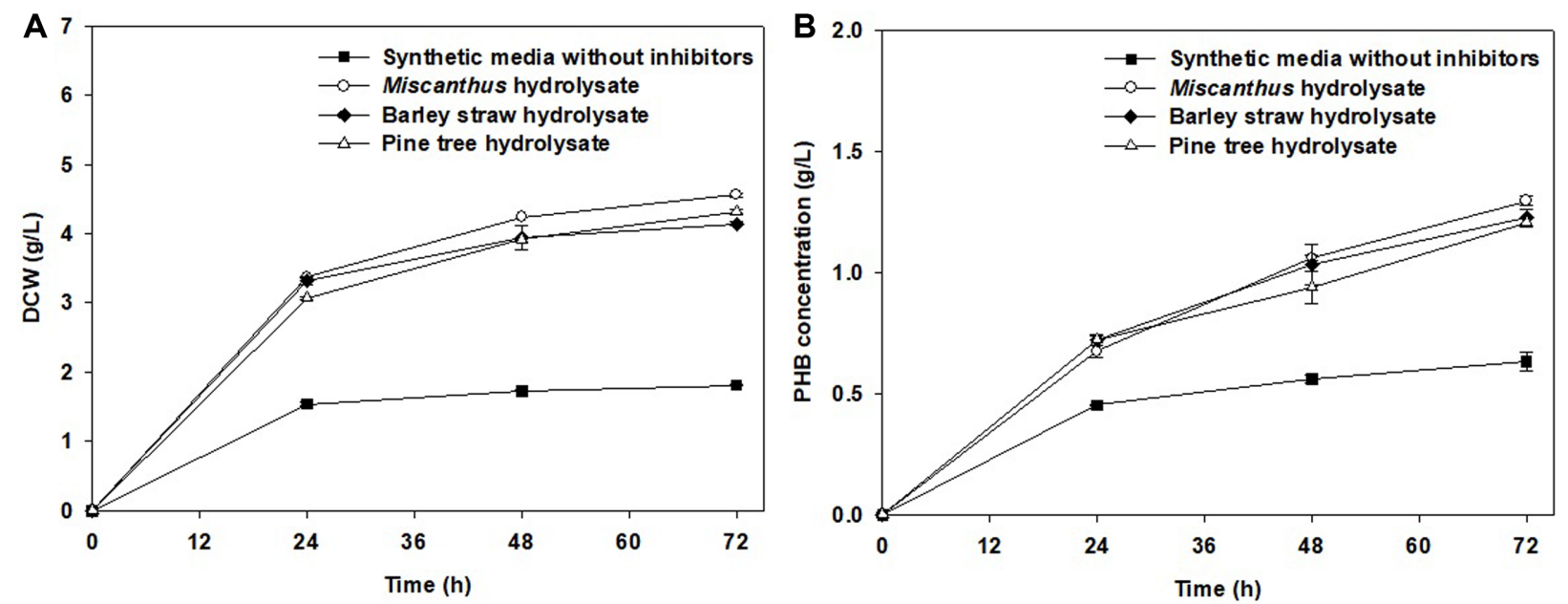

Fig. 5. Polyhydroxybutyrate (PHB) production using lignocellulose hydrolysates.

Cell growth and PHB production in E. coli YH090 (pLW487) using lignocellulose hydrolysates were compared. Lignocellulose hydrolysates from Miscanthus, barley straw, and pine tree were used. (A) DCW (dry cell weight, g/l) and (B) PHB concentration (g/l). Cells were grown for $72 \mathrm{~h}$. Error bars represent the standard deviation of two replicates.

to synthetic medium without any inhibitor. When lignocellulose hydrolysates containing well-known fermentation inhibitors (formic acid, 5-hydroxymethylfurfural, and furfural) were used, PHB production was increased compared to that in synthetic medium. Although it cannot be definitively concluded that the inhibitors increase PHB production, the results indicate that PHB production is possible in lignocellulose hydrolysates in the presence of inhibitors such as furfural, vanillin, and 4-hydroxybenzaldehyde.

\section{Discussion}

For efficient utilization of lignocellulose as a sugar source, a pretreatment process, such as acid hydrolysis, is required [6, 7]. However, in the pretreatment process, several fermentation inhibitors are formed in addition to monosaccharides [11, 12]. In particular, furfural is considered one of the major inhibitors of E. coli growth [41].

Here, we report the protective effect of PHB on growth inhibition by furfural and the stimulating effect of furfural on PHB production. Although the mechanisms underlying these effects still need to be investigated, we demonstrated the synergetic effects of furfural and PHB production and the feasibility of PHB production in the presence of lignocellulose hydrolysates. We showed that these effects were not related to a supplemental carbon source (Fig. 1C) or to only one of the enzymes in the PHB synthesis pathway (Fig. 3). In other words, the cell growth inhibition effect of furfural was restored by overexpression of three PHB synthetic genes in E. coli KSYH(DE3). In particular, PHB production was increased in the presence of furfural compared to in its absence.

Multiple reports have described that PHA formation and mobilization enhance stress tolerance [45-47]. A previous study indicated that a complete PHB mobilization system (expression of PHB synthetic genes and PHB depolymerase) serves as an intracellular energy and carbon storage system in E. coli, and it increases tolerance to stress conditions, such as carbon starvation, heat shock, and osmotic pressure [46]. In addition, PHA mobilization influences chaperone protein levels [37,45]. It is well known that PHB accumulation in recombinant $E$. coli can cause stress in cells and induces the expression of various protective proteins related to stress resistance (e.g., heat shock proteins, such as GroEL, GroES, and DnaK) [45]. Therefore, stress responses might be responsible for the increased cell growth and PHB production in the presence of furfural. In conclusion, PHB synthetic genes can improve tolerance to toxic inhibitors, such as furfural, vanillin, and 4-hydroxybenzaldehyde. In addition, although these are well-known fermentation inhibitors, they could be used to stimulate PHB production. PHB production by E. coli YH090 in the presence of lignocellulose hydrolysates was approximately 2-fold higher than that in the synthetic medium. Consequently, PHB production in recombinant $E$. coli using lignocellulose hydrolysates could be useful for cost-effective bio-based plastic production. 


\section{Acknowledgments}

This study was supported by the Research Program for Solving Social Issues of the National Research Foundation of Korea (NRF) funded by the Ministry of Science and ICT (2017M3A9E4077234), National Research Foundation of Korea (NRF) (NRF-2015M1A5A1037196, NRF2016R1D1A1B03932301). Consulting service from the Microbial Carbohydrate Resource Bank (MCRB, Seoul, Korea) was kindly appreciated. This work was also supported by the Polar Academic Program (PAP,PE18900).

\section{Conflict of Interest}

The authors have no financial conflicts of interest to declare.

\section{References}

1. Ragauskas AJ, Williams CK, Davison BH, Britovsek G, Cairney J, Eckert CA, et al. 2006. The path forward for biofuels and biomaterials. Science 311: 484-489.

2. Lynd LR, Laser MS, Bransby D, Dale BE, Davison B, Hamilton R, et al. 2008. How biotech can transform biofuels. Nat. Biotechnol. 26: 169-172.

3. Sims RE, Mabee W, Saddler JN, Taylor M. 2010. An overview of second generation biofuel technologies. Bioresour. Technol. 101: 1570-1580.

4. Brodin M, Vallejos M, Opedal MT, Area MC, ChingaCarrasco G. 2017. Lignocellulosics as sustainable resources for production of bioplastics-a review. J. Clean Prod. 162: 646-664.

5. Sharma HK, Xu C, Qin W. 2017. Biological pretreatment of lignocellulosic biomass for biofuels and bioproducts: an overview. Waste and Biomass Valorization. 1-17.

6. Carroll A, Somerville C. 2009. Cellulosic biofuels. Annu. Rev. Plant Biol. 60: 165-182.

7. Weijde Tvd, Alvim Kamei CL, Torres AF, Vermerris W, Dolstra O, Visser RGF, et al. 2013. The potential of C4 grasses for cellulosic biofuel production. Front. Plant Sci. 4: 107.

8. Bhatia SK, Gurav R, Choi T-R, Jung H-R, Yang S-Y, Moon $\mathrm{Y}-\mathrm{M}$, et al. 2019. Bioconversion of plant biomass hydrolysate into bioplastic (polyhydroxyalkanoates) using Ralstonia eutropha 5119. Bioresour. Technol. 271: 306-315.

9. Kumar P, Barrett DM, Delwiche MJ, Stroeve P. 2009. Methods for pretreatment of lignocellulosic biomass for efficient hydrolysis and biofuel production. Ind. Eng. Chem. 48: 3713-3729.

10. Sun Y, Cheng J. 2002. Hydrolysis of lignocellulosic materials for ethanol production: a review. Bioresour. Technol. 83: 1-11.
11. Mills TY, Sandoval NR, Gill RT. 2009. Cellulosic hydrolysate toxicity and tolerance mechanisms in Escherichia coli. Biotechnol. Biofuels 2: 26.

12. Saha BC. 2003. Hemicellulose bioconversion. J. Ind. Microbiol. Biotechnol. 30: 279-291.

13. Gorsich S, Dien B, Nichols N, Slininger P, Liu Z, Skory C. 2006. Tolerance to furfural-induced stress is associated with pentose phosphate pathway genes ZWF1, GND1, RPE1, and TKL1 in Saccharomyces cerevisiae. Appl. Microbiol. Biotechnol. 71: 339-349.

14. Barciszewski J, Siboska GE, Pedersen BO, Clark BF, Rattan SI. 1997. A mechanism for the in vivo formation of N6furfuryladenine, kinetin, as a secondary oxidative damage product of DNA. FEBS Lett. 414: 457-460.

15. Palmqvist E, Hahn-Hägerdal $\quad$ B. 2000. Fermentation of lignocellulosic hydrolysates. II: inhibitors and mechanisms of inhibition. Bioresour. Technol. 74: 25-33.

16. Zaldivar J, Martinez A, Ingram LO. 2000. Effect of alcohol compounds found in hemicellulose hydrolysate on the growth and fermentation of ethanologenic Escherichia coli. Biotechnol. Bioeng. 68: 524-530.

17. Song H-S, Jeon J-M, Kim H-J, Bhatia SK, Sathiyanarayanan G, $\mathrm{Kim} \mathrm{J}$, et al. 2017. Increase in furfural tolerance by combinatorial overexpression of NAD salvage pathway enzymes in engineered isobutanol-producing E. coli. Bioresour. Technol. 245: 1430-1435.

18. Seo H-M, Jeon J-M, Lee JH, Song H-S, Joo H-B, Park S-H, et al. 2016. Combinatorial application of two aldehyde oxidoreductases on isobutanol production in the presence of furfural. J. Ind. Microbiol. Biotechnol. 43: 37-44.

19. Wang X, Miller E, Yomano L, Zhang X, Shanmugam K, Ingram L. 2011. Increased furfural tolerance due to overexpression of NADH-dependent oxidoreductase FucO in Escherichia coli strains engineered for the production of ethanol and lactate. Appl. Environ. Microbiol. 77: 5132-5140.

20. Wang X, Yomano LP, Lee JY, York SW, Zheng H, Mullinnix MT, et al. 2013. Engineering furfural tolerance in Escherichia coli improves the fermentation of lignocellulosic sugars into renewable chemicals. Proc. Natl. Acad. Sci. USA 110: 40214026.

21. Madkour MH, Heinrich D, Alghamdi MA, Shabbaj, II, Steinbuchel A. 2013. PHA recovery from biomass. Biomacromolecules 14: 2963-2972.

22. Steinbuchel A, Fuchtenbusch B. 1998. Bacterial and other biological systems for polyester production. Trends. Biotechnol. 16: 419-427.

23. Wen Q, Chen Z, Tian T, Chen W. 2010. Effects of phosphorus and nitrogen limitation on PHA production in activated sludge. J. Environ. Sci. 22: 1602-1607.

24. Johnson K, Kleerebezem R, van Loosdrecht MC. 2010. Influence of the $\mathrm{C} / \mathrm{N}$ ratio on the performance of polyhydroxybutyrate (PHB) producing sequencing batch reactors at short SRTs. Water Res. 44: 2141-2152. 
25. Ahn J, Jho EH, Nam K. 2015. Effect of $\mathrm{C} / \mathrm{N}$ ratio on polyhydroxyalkanoates (PHA) accumulation by Cupriavidus necator and its implication on the use of rice straw hydrolysates. Environ. Eng. Res. 20: 246-253.

26. Sudesh K, Abe H, Doi Y. 2000. Synthesis, structure and properties of polyhydroxyalkanoates: biological polyesters. Prog. Polym. Sci. 25: 1503-1555.

27. Du C, Sabirova J, Soetaert W, Lin C. 2012. Polyhydroxyalkanoates production from low-cost sustainable raw materials. Curr. Chem. Biol. 6: 14-25.

28. Broeren M. 2013. Production of Bio-ethylene-Technology Brief. IEA-ETSAP \& IRENA, International Renewable Energy Agency.

29. Cesário MT, Raposo RS, de Almeida MCM, van Keulen F, Ferreira BS, da Fonseca MMR. 2014. Enhanced bioproduction of poly-3-hydroxybutyrate from wheat straw lignocellulosic hydrolysates. N. Biotechnol. 31: 104-113.

30. Yu J, Stahl H. 2008. Microbial utilization and biopolyester synthesis of bagasse hydrolysates. Bioresour. Technol. 99: 8042-8048.

31. Silva L, Taciro M, Ramos MM, Carter J, Pradella J, Gomez J. 2004. Poly-3-hydroxybutyrate (P3HB) production by bacteria from xylose, glucose and sugarcane bagasse hydrolysate. $J$ Ind. Microbiol. Biotechnol. 31: 245-254.

32. Dietrich D, Illman B, Crooks C. 2013. Differential sensitivity of polyhydroxyalkanoate producing bacteria to fermentation inhibitors and comparison of polyhydroxybutyrate production from Burkholderia cepacia and Pseudomonas pseudoflava. BMC Res. Notes 6: 219.

33. Wang W, Yang S, Hunsinger GB, Pienkos PT, Johnson DK. 2014. Connecting lignin-degradation pathway with pretreatment inhibitor sensitivity of Cupriavidus necator. Front. Microbiol. 5: 247.

34. Dietrich K, Dumont M-J, Schwinghamer T, Orsat V, Del Rio LF. 2017. Model study to assess softwood hemicellulose hydrolysates as the carbon source for PHB production in Paraburkholderia sacchari IPT 101. Biomacromolecules 19: 188200.

35. Yang YH, Brigham C, Song E, Jeon JM, Rha C, Sinskey A. 2012. Biosynthesis of poly (3-hydroxybutyrate-co-3hydroxyvalerate) containing a predominant amount of 3hydroxyvalerate by engineered Escherichia coli expressing propionate-CoA transferase. J. Appl. Microbiol. 113: 815-823.

36. Jeon JM, Kim HJ, Bhatia SK, Sung C, Seo HM, Kim JH, et al. 2017. Application of acetyl-CoA acetyltransferase (AtoAD) in Escherichia coli to increase 3-hydroxyvalerate fraction in poly (3-hydroxybutyrate-co-3-hydroxyvalerate). Bioproc. Biosyst. Eng. 40: 781-789.

37. Mezzina MP, Wetzler DE, Almeida A, Dinjaski N, Prieto MA, Pettinari MJ. 2015. A phasin with extra talents: a polyhydroxyalkanoate granule-associated protein has chaperone activity. Environ. Microbiol. 17: 1765-1776.

38. Phylactides M. 1997. Molecular biology series 3. Tools of molecular biology: gene cloning. Br. J. Hosp. Med. 57: 49-50.

39. Braunegg G, Sonnleitner B, Lafferty R. 1978. A rapid gas chromatographic method for the determination of poly- $\beta$ hydroxybutyric acid in microbial biomass. Appl. Microbiol. Biotechnol. 6: 29-37.

40. Bhatia SK, Kim J, Song H-S, Kim HJ, Jeon J-M, Sathiyanarayanan G, et al. 2017. Microbial biodiesel production from oil palm biomass hydrolysate using marine Rhodococcus sp. YHY01. Bioresour. Technol. 233: 99-109.

41. Zaldivar J, Ingram LO. 1999. Effect of organic acids on the growth and fermentation of ethanologenic Escherichia coli LY01. Biotechnol. Bioeng. 66: 203-210.

42. Song HS, Jeon JM, Choi YK, Kim JY, Kim W, Yoon JJ, et al. 2017. L-Glycine Alleviates Furfural-Induced Growth Inhibition during Isobutanol Production in Escherichia coli. J. Microbiol.Biotechnol. 27: 2165-2172.

43. Nieves LM, Panyon LA, Wang X. 2015. Engineering sugar utilization and microbial tolerance toward lignocellulose conversion. Front. Bioeng. Biotechnol. 3: 17.

44. Moon J, Liu ZL. 2015. Direct enzyme assay evidence confirms aldehyde reductase function of Ydr541cp and Yg1039wp from Saccharomyces cerevisiae. Yeast 32: 399-407.

45. Han M-J, Yoon SS, Lee SY. 2001. Proteome analysis of metabolically engineeredescherichia coli producing poly (3hydroxybutyrate). J Bacteriol. 183: 301-308.

46. Wang Q, Yu H, Xia Y, Kang Z, Qi Q. 2009. Complete PHB mobilization in Escherichia coli enhances the stress tolerance: a potential biotechnological application. Microb. Cell Fact. 8: 47 .

47. James BW, Mauchline WS, Dennis PJ, Keevil CW, Wait R. 1999. Poly-3-hydroxybutyrate in Legionella pneumophila, an energy source for survival in low-nutrient environments. Appl. Environ Molecular biology series 3. Tools of molecular biology: gene cloning. Microbiol. 65: 822-827.

48. Yang YH, Brigham C, Willis L, Rha C, Sinskey A. 2011. Improved detergent-based recovery of polyhydroxyalkanoates (PHAs). Biotechnology Lett. 33: 937-942. 